\author{
Marquette University \\ e-Publications@Marquette
}

Civil and Environmental Engineering Faculty

Research and Publications

Civil, Construction, and Environmental

Engineering, Department of

\title{
2-2021
}

\section{Behavior and Modeling of Circular Large Rupture Strain FRP- Confined Ice under Axial Compression}

\author{
Yanlei Wang \\ Dalian University of Technology \\ Guipeng Chen \\ Dalian University of Technology \\ Baolin Wan \\ Marquette University, baolin.wan@marquette.edu \\ Gaochuang Cai \\ University of Lyon \\ Baoguo Han \\ Dalian University of Technology
}

Follow this and additional works at: https://epublications.marquette.edu/civengin_fac

Part of the Civil Engineering Commons

\section{Recommended Citation}

Wang, Yanlei; Chen, Guipeng; Wan, Baolin; Cai, Gaochuang; and Han, Baoguo, "Behavior and Modeling of Circular Large Rupture Strain FRP-Confined Ice under Axial Compression" (2021). Civil and Environmental Engineering Faculty Research and Publications. 283.

https://epublications.marquette.edu/civengin_fac/283 
Marquette University

e-Publications@Marquette

\section{Civil, Construction and Environmental Engineering Faculty Research and Publications/College of Engineering}

This paper is NOT THE PUBLISHED VERSION.

Access the published version via the link in the citation below.

Journal of Composites for Construction, Vol. 25, No. 1 (February 2021): 04020076. DOI. This article is (C) American Society of Civil Engineers and permission has been granted for this version to appear in $\underline{\text { e- }}$ Publications@Marquette. American Society of Civil Engineers does not grant permission for this article to be further copied/distributed or hosted elsewhere without express permission from American Society of Civil Engineers.

\section{Behavior and Modeling of Circular Large Rupture Strain FRP-Confined Ice under Axial Compression}

\section{Yanlei Wang}

State Key Laboratory of Coastal and Offshore Engineering, School of Civil Engineering, Dalian University of Technology, Dalian 116024, China

Guipeng Chen

State Key Laboratory of Coastal and Offshore Engineering, School of Civil Engineering, Dalian University of Technology, Dalian 116024, China

Baolin Wan

Department of Civil, Construction and Environmental Engineering, Marquette University, Milwaukee, WI

\section{Gaochuang Cai}

Laboratoire de Tribologie et de Dynamique des Systèmes, Ecole Nationale d'Ingénieurs de SaintEtienne, University Lyon, UMR 5513, 58 Rue Jean Parot, 42023 SaintEtienne Cedex 2, France

Baoguo Han 
State Key Laboratory of Coastal and Offshore Engineering, School of Civil Engineering, Dalian University of Technology, Dalian 116024, China

\section{Abstract}

The application of concrete is severely limited in construction in cold areas. However, the local ice has functioned as a potential substitute for concrete for a long time. In order to make efficient use of ice to overcome its weaknesses of low strength and poor ductility, an innovative type of ice-filled large rupture strain (LRS) fiber-reinforced polymer (FRP) tube column was developed. The system consists of external LRS FRP tubes filled with plain ice or sawdust-reinforced ice. This paper presents an experimental investigation into the axial compressive behavior of such composite stub columns with circular sections. The test results confirmed that the axial compressive behavior of the ice cores was greatly improved because of the LRS FRP confinement, as well as the addition of sawdust in ice. The axial stress-strain curves of the LRS FRP-confined ice exhibited monotonically ascending bilinear shapes. Both the compressive strength and the ultimate axial strain of the confined ice were significantly enhanced with an increase of the thickness of the LRS FRP tube. A theoretical model for the LRS FRP-confined ice is proposed, in which the dilation properties (i.e., lateral strain-axial strain relation), as well as the entire axial stress-strain responses of the inner ice cores, are explicitly modeled with reasonable accuracy.

\section{Introduction}

The use of concrete is severely limited in construction in cold areas (e.g., polar regions) because the low temperature makes it difficult to mix, cast, and cure concrete (Wang et al. 2018a, b). Moreover, it is not economical to transport the constituent materials of concrete to such areas. However, the available natural ice has been applied in construction much earlier than the emergence of concrete. Many buildings or infrastructures were constructed with ice, such as the igloos of the Eskimos, the ice hotel in Sweden (Pinto 2016), the ice road in Canada (Mesher and Proskin 2008), the ice bridge (Michel et al. 1974), and the polar runways (White and McCallum 2018). A number of investigations (Schulson 2001; Iliescu and Schulson 2002; Petrovic 2003; Masterson 2009) have been carried out to study the behavior of plain ice subjected to uniaxial compression. The engineering properties of freshwater ice and sea ice were reviewed by Gold (1977) and Timco and Weeks (2010), respectively. Ice is characterized as a brittle material with weak strength (Masterson 2009), which is far lower than the strength of concrete (Wang et al. 2020b, c). The weaknesses of ice, such as low strength and brittle nature, greatly restrict its broader applications in civil engineering.

In order to improve the mechanical properties of plain ice, various materials such as pulp fibers (Wu et al. 2020), alluvium (Nixon 1989), fiberglass net and cloth (Vasiliev 1993), sand (Nixon and Weber 1991, 1995), newspaper, and sodium carboxyl methyl cellulose-gelatin polyelectrolyte complexes (Li et al. 2015) were introduced into the ice matrix as reinforcement. It was observed that the bearing capacity and especially the deformability of the ice specimens were greatly enhanced due to the introduction of such reinforcing materials. In addition, Pykrete (a combination of sawdust and water at a weight ratio of 14:86), originally proposed by Geoffrey Pyke, was even planned to be used to construct aircraft carriers during the Second World War (Perutz 1948). Vasiliev et al. (2015) investigated the behavior of ice cylinders reinforced by wood-based materials under axial compression at $-18^{\circ} \mathrm{C}$ and indicated that 
the ultimate strength of the composite ice was more than twice greater than that of the ice without reinforcement. With regard to the reinforced ice structures, a scale model of the Sagrada Familia was built up with the sawdust-reinforced ice in Finland in 2015 (Vasiliev et al. 2015). More recently, the Flamenco Ice Tower with a height of 30.5 m was constructed, in Harbin, in 2017, by spraying a mixture of cellulose and water on an inflatable mold (Pronk et al. 2019). These two successful engineering cases confirmed the possibility of using reinforced ice as a construction material. However, a very limited enhancement in the strength of ice can be achieved by means of introducing various reinforcing materials. The peak stress of the resulting reinforced ice was generally between 4 and 13 MPa (Vasiliev 1993; Vasiliev et al. 2015), which is still far lower than that of normal concrete. Furthermore, rapid degradation of the material properties may occur due to the chemicals in its surrounding environment and the solar radiation when a structure or structural member constructed by reinforced ice is directly exposed to the harsh environment in cold regions.

Fiber-reinforced polymer (FRP) composites including carbon FRP (CFRP), glass FRP (GFRP), aramid FRP (AFRP), and basalt FRP (BFRP) are commonly used as confining jackets (i.e., wrap and tube) for concrete members (Wang et al. 2018c, d; Li et al. 2019; Cao et al. 2020; Shi et al. 2020; Wei et al. 2020). They are herein referred to as conventional FRP for brevity. FRP confinement belongs to passive confinement because the confining pressure provided by the FRP jacket experiences a continuous increase with the dilation of the inner concrete until the final rupture of the FRP (Lam and Teng 2003; Li et al. 2018b). It has been well understood that the peak stress, as well as the corresponding axial strain of the concrete core, would be greatly improved after the lateral confinement from the conventional FRP wrap in retrofitting (Xiao and Wu 2000; Lam and Teng 2003; Lin and Teng 2017; Cui and Sheikh 2010) or the conventional FRP tube in new construction (Fam and Rizkalla 2001; Mohamed and Masmoudi 2010; Yu and Teng 2011; Cao et al. 2017; Li et al. 2018b; Wang et al. 2019, 2020a; Zhang et al. 2020). However, the production of the conventional FRP consumes large amounts of energy. In addition, the ultimate state of FRP-confined concrete is usually dominated by the relatively small hoop strain capacity of the FRP jackets in composite members. New types of FRP composites consisting of polytheylene naphthalate (PEN) or polyethylene terephthalate (PET) fibers have emerged against this background (Bai et al. 2019, 2020). The PEN and PET fibers are characterized by their large rupture strain (LRS) generally exceeding $5 \%$, which is much greater than that of the aforementioned conventional FRP within 1.5\%-3.0\% (Bai et al. 2019). In addition, the LRS fibers are produced from recycled plastic bottles, leading to a more economic and environmentally friendly solution (Bai et al. 2019). A series of tests have been conducted to study the axial compressive behavior of circular LRS FRP-confined concrete stub columns (Dai et al. 2011; Ispir 2015; Saleem et al. 2017; Bai et al. 2019; Pimanmas and Saleem 2019; Zeng et al. 2020a, b), which confirmed that the bearing capacity and especially the deformability of the composite column were considerably enhanced by the LRS FRP confinement.

Considering the good structural performance of FRP-confined concrete columns and the excellent characteristics of LRS FRP composites, an innovative type of ice-filled large rupture strain (LRS) fiberreinforced polymer (FRP) tube column was developed. The system consists of external LRS FRP tubes that are filled with ice with or without sawdust. There are mainly five advantages of this type of columns from the perspective of mechanics and durability. First, the bearing strength and deformability of the inner ice core are considerably improved by the external LRS FRP confinement, as 
well as the inclusion of sawdust in ice. Second, the inner ice is well isolated from the surrounding environmental disturbance due to the outer LRS FRP tube with good thermal insulation, thus delaying the melting of ice cores. Third, the corrosion-resistant FRP tubes can be filled with both freshwater ice and sea ice, leading to more durable columns with much longer service life than ice-filled steel tube columns (Wang et al. 2018a, b). Moreover, the longitudinal modulus of an FRP tube is much smaller than that of a steel tube. Therefore, more contribution of the FRP tube is to provide lateral confinement to the ice core instead of directly helping to share the axial load. The combination of ice and FRP is expected to achieve a better composite action than combination of ice and steel. Fourth, the orientation of the reinforcing fibers in the FRP tube can be artificially controlled according to the requirements. Despite its relatively high price compared to steel, FRP may still be a better choice to confine ice due to its outstanding design and manufacture flexibility. Finally, the Poisson's ratio of ice (around 0.3) is not sensitive to ice temperatures (Gammon et al. 1983; Sinha 1989; Staroszczyk 2019). It is larger than Poisson's ratio of concrete (approximately 0.2), which means that ice dilates more severely than concrete, corresponding to the same axial shortening. Therefore, the potential of the LRS FRP's large strain capacity might be fully developed when working with the inner ice. In addition, the inner ice itself also has some advantages from the point of view of environmental protection. Ice becomes water after thawing, while sawdust is a biodegradable byproduct material with low price.

It is envisioned that the proposed ice-filled LRS FRP tube columns could be used in the following scenarios. First, ice is a very suitable material for winter amusement, such as ice and snow sculptures and other recreational buildings (e.g., ice hotel), which attracts many visitors from all over the world (Dewar et al. 2001). The ice columns in an ice building may be replaced by the proposed columns with a much higher bearing capacity. The cross-sectional areas of the ice columns are expected to be effectively reduced, thus increasing usable spaces. Moreover, the pedestal of an ice sculpture could be constructed with the proposed ice column, which would bring the sculpture to a higher landscape with great magnificence. Besides the winter amusement, ice has been used to build unheated structures, such as those used for storage or temporary shelters (Makkonen 1994). Therefore, the proposed columns could be used to build the supporting structures of these unheated storage or temporary shelters, such as staging posts for the scientific expedition team on the way to polar regions. In addition, the proposed columns have great potential to be used as temporary piers of ice bridges or compression members of the polar research stations. Based on the imaginations and creativities of architects and engineers, the proposed columns may have other applications.

This study presents a systematic experimental program on the behavior of the newly proposed icefilled LRS FRP tube stub columns with circular sections subjected to uniaxial loads. The key variables are the LRS FRP confinement level and the incorporation of sawdust in ice. Theoretical models for the LRS FRP-confined ice are proposed, which are used to explicitly evaluate the dilation properties (i.e., lateral strain-axial strain relation) as well as the entire axial stress-strain behavior of the inner ice cores. 


\section{Experimental Program}

\section{Test Specimens}

The experimental program involved nine circular plain ice-filled LRS FRP tube (IFFT) specimens and nine circular sawdust-reinforced ice-filled LRS FRP tube (SFFT) specimens. Six unconfined ice cylinders with and without sawdust were also designed as counterparts. All specimens were designed to have a height of $300 \mathrm{~mm}$ and a nominal core diameter of $150 \mathrm{~mm}$. The main parameters involved the LRS FRP confinement and the incorporation of sawdust. Three nominally identical specimens were axially loaded in each group. Each specimen has a name, and the naming rule is described as follows: (1) two letters PI, SI, IF, or SFto represent plain ice specimen, sawdust-reinforced ice specimen, IFFT specimen, or SFFT specimen, respectively; (2) second numeral $0,1,2$, or 3 to represent the plies of LRS FRP layers; and (3) a final Roman numeral to differentiate the nominally identical specimens within the same series. The details of all specimens are summarized in Table 1. The nominal thickness, $t$, of the LRS FRP tube without considering epoxy resin was obtained by the nominal thickness of the LRS FRP sheet, while the actual thickness, $t_{a}$, of the LRS FRP tube with considering epoxy resin was measured from the prepared LRS FRP tube. As shown in Table 1, the values of $t_{a}$ were much larger than those of $t$ due to the inclusion of epoxy resin.

Table 1. Details of test specimens and key test results

\begin{tabular}{|c|c|c|c|c|c|c|c|c|}
\hline Series & Specimen & $\begin{array}{l}\text { Type of ice } \\
\text { core }\end{array}$ & \begin{tabular}{|l|} 
FRP \\
tube
\end{tabular} & & & $\begin{array}{l}\text { Test } \\
\text { results }\end{array}$ & & \\
\hline & & & Ply & $\begin{array}{l}t \\
\text { (mm) }\end{array}$ & $\begin{array}{l}t_{a} \\
\text { (mm) }\end{array}$ & $N_{e}(\mathrm{kN})$ & $\begin{array}{l}\text { Average } N_{e} \\
\text { (kN) }\end{array}$ & $k$ \\
\hline PI & PIO-I & $\mathrm{Pl}$ & - & - & - & 49.8 & 49.0 & \begin{tabular}{|l|}
1.54 \\
\end{tabular} \\
\hline PIO-II & 48.2 & & & & & & & \\
\hline PIO-III & 49.0 & & & & & & & \\
\hline SI & SIO-I & $\mathrm{SI}$ & - & - & - & 74.8 & 75.6 & \\
\hline SIO-II & 75.6 & & & & & & & \\
\hline SI-III & 76.4 & & & & & & & \\
\hline IF1 & IF1-I & $\mathrm{PI}$ & 1 & 0.841 & 3.55 & 271 & 282 & 1.17 \\
\hline IF1-II & 284 & & & & & & & \\
\hline IF1-III & 290 & & & & & & & \\
\hline SF1 & SF1-I & $\mathrm{SI}$ & 1 & 0.841 & 3.55 & 339 & 329 & \\
\hline SF1-II & 338 & & & & & & & \\
\hline SF1-III & 309 & & & & & & & \\
\hline IF2 & IF2-I & $\mathrm{PI}$ & 2 & 1.682 & 4.98 & 380 & 400 & 1.13 \\
\hline IF2-II & 414 & & & & & & & \\
\hline IF2-III & 406 & & & & & & & \\
\hline SF2 & SF2-I & SI & 2 & 1.682 & 4.98 & 456 & 451 & \\
\hline SF2-II & 437 & & & & & & & \\
\hline SF2-III & 459 & & & & & & & \\
\hline IF3 & IF3-I & $\mathrm{PI}$ & 3 & 2.523 & 7.37 & 590 & 591 & 1.03 \\
\hline IF3-II & 576 & & & & & & & \\
\hline IF3-III & 608 & & & & & & & \\
\hline $\mathrm{SF} 3$ & SF3-I & $\mathrm{SI}$ & 3 & 2.523 & 7.37 & 623 & 609 & \\
\hline
\end{tabular}




\begin{tabular}{|l|l|l|l|l|l|l|l|l|}
\hline SF3-II & 589 & & & & & & & \\
\hline SF3-III & 615 & & & & & & & \\
\hline
\end{tabular}

The LRS FRP tubes in this study were formed via a wet lay-up process by wrapping PET FRP sheets around the mold, with the fibers oriented in the hoop direction and the overlapping zone being 150 $\mathrm{mm}$. In addition, 40-mm-wide CFRP strips were applied at the two ends of the LRS FRP tubes to prevent possible failure near such areas during the compression test. Dry pine sawdust with a particle length of around $2.5 \mathrm{~mm}$ was used to prepare the sawdust-reinforced ice specimens. The compressive behavior of ice columns is affected by the weight ratio of sawdust to water (Vasiliev et al. 2015). In order to obtain an optimum weight ratio, trial tests on sawdust-reinforced ice specimens with different proportions of sawdust (i.e., 7\%, 10\%, 14\%, and 18\%) were conducted by Wang et al. (2020c). The test results showed that the sawdust-reinforced ice columns with $14 \%$ sawdust in weight achieved the best compressive properties among all specimens. Therefore, the sawdust and water were mixed together at a weight ratio of 14:86 in this study. The mixture was placed in a container at ambient temperature for $3 \mathrm{~h}$ to make the sawdust sufficiently saturated. Even distribution of the sawdust in water is needed to ensure good compressive behavior of the resulting sawdust-reinforced ice (Vasiliev et al. 2015). Therefore, mechanical stirring was conducted for $10 \mathrm{~min}$ to get a slurry-like mixture. The mixture was then casted into different molds (i.e., PVC tubes for unconfined specimens and FRP tubes for confined specimens) and compacted layer by layer (five layers in total) to ensure a relatively even distribution of the sawdust and to release the bubbles during casting. For the plain ice specimens, water was poured into PVC and FRP tubes to make unconfined and confined ice specimens, respectively. All specimens were placed in a freezer set at a temperature of $-15^{\circ} \mathrm{C}$ for $48 \mathrm{~h}$. The two ends of each unconfined ice specimen were further wrapped with a 45-mm-wide duct tape before the compression tests to avoid premature failure near ends. Fig. 1 shows the unconfined and confined ice stub columns before testing. A relatively even distribution of the sawdust was achieved in the sawdust-reinforced ice specimens, as shown in Fig. 1(b).

Although this research focuses on the lab testing and stress-strain model for the proposed ice-filled LRS FRP tube stub columns, the process of constructing such columns at the actual construction site is also envisaged and briefly introduced in the following. First, a prefabricated LRS FRP tube is erected on the site and fixed with a supporting frame. The bottom of the tube is sealed to form a waterproof stayin-place formwork. Second, FRP bars or FRP pultrusion profiles are placed in the formwork. These additional reinforcements were not included in the current laboratory tests. This difference is explained as follows. In an actual ice structure, the LRS FRP-confined ice columns may be subjected to the combined action of the axial load and moment. The interfacial bond between the FRP tube and the ice may be weakened by the possible local melting of ice, thus reducing the flexural capacity of the composite column. In order to improve the bearing capacity of the stub column under both compression and bending, additional corrosion-resistant reinforcement (e.g., FRP bars or FRP pultrusion profiles) should be placed in the FRP tube to help resist the bending moment. However, the main aim of this study is to propose a stress-strain model for the LRS FRP-confined ice. In order to eliminate the effect of additional reinforcement on the inner ice, the reinforcement was not included in the test specimens in this study. Third, water is obtained by heating the local ice blocks or pumping from the unfrozen water under the ice. The sawdust and water are mixed at the designed weight ratio 
and fully stirred before casting. Fourth, the sawdust and water mixture is cast into the FRP tube layer by layer, which is similar to the preparation of the specimens in the laboratory. Finally, the composite column is achieved after the water freezes inside the tube.

\section{Material Properties}

A unidirectional PET-600 FRP sheet (nominal thickness $=0.841 \mathrm{~mm}$ ) was used to make the LRS FRP tubes. In accordance with ASTM D3039/D3039M-17 (ASTM 2017), five LRS FRP coupons were prepared and tested in tension. The tensile stress-strain curves for LRS FRP exhibited approximately bilinear shapes (Fig. 2), which is fundamentally different from the linear responses of conventional FRP. It is generally accepted that the tensile responses of FRP mainly depend on its reinforcing fibers instead of the resin matrix. In terms of microstructural morphology, a single PET fiber is composed of microfibrils aligned along the fiber axis. These microfibrils consist of an alternation of an amorphous phase, a crystalline phase, and a mesomorphous phase (an intermediate phase). The successive loading of these phases, including the alignment of amorphous chains, loading of the polymer backbone, and the sliding or failing of the macromolecular chains, results in the variation of the tensile modulus of a PET fiber (Lechat et al. 2011). The tensile response of a single PET fiber is characterized by an approximately bilinear shape, which contributes to the nonlinear feature of the LRS FRP, as shown in Fig. 2. The average tensile strength, $f_{u}$, and ultimate tensile strain, $\varepsilon_{f}$, of the LRS FRP as well as the corresponding standard deviations were $789 \pm 13.8 \mathrm{MPa}$ and $8.59 \% \pm 0.19 \%$, respectively. According to Bai et al. (2019), the slope of the first linear branch was defined as the first elastic modulus, $E_{\mathrm{fr} 1}$, and the slope of the second linear branch was referred to as the second elastic modulus, $E_{\mathrm{frp}}$. The average values of $E_{\text {frp } 1}$ and $E_{\text {frp2 }}$ as well as the corresponding standard deviations were $17.8 \pm 0.6$ and $8.5 \pm 0.2 \mathrm{GPa}$, respectively.

The bilinear expression, originally proposed by Bai et al. (2019), was used in this study to describe the stress-strain responses of LRS FRP:

$$
\sigma_{\mathrm{frp}}= \begin{cases}E_{\mathrm{frp} 1} \varepsilon_{\mathrm{frp}}, & \varepsilon_{\mathrm{frp}} \leq \varepsilon_{\mathrm{frp} 0} \\ E_{\mathrm{frp} 2} \varepsilon_{\mathrm{frp}}+C, & \varepsilon_{\mathrm{frp}}>\varepsilon_{\mathrm{frp} 0}\end{cases}
$$

where $\sigma_{\mathrm{frp}}$ and $\varepsilon_{\mathrm{frp}}=$ tensile stress and strain of LRS FRP, respectively; $C=$ intercept of the vertical axis by the second linear branch $\left(C=70 \mathrm{MPa}\right.$ in this study); and $\varepsilon_{\mathrm{frpo}}=$ material turning strain at which the two linear portions are connected ( $\varepsilon_{\mathrm{frpo}}=0.75 \%$ in this study).

It should be noted that the mechanical properties of FRP are affected by the low temperature in cold regions, which has been well documented in the existing literature works (Reed and Golda 1994; Schutz 1998; Nardone et al. 2012; Feng et al. 2016). The material properties of FRP tend to be enhanced with the decrease of the temperature from $295 \mathrm{~K}\left(21.85^{\circ} \mathrm{C}\right)$ to $4 \mathrm{~K}\left(-269.15^{\circ} \mathrm{C}\right)$ (Reed and Golda 1994; Schutz 1998). The tensile tests reported by Nardone et al. (2012) revealed that the tensile strength and elastic modulus of FRP were slightly increased when the temperature was decreased from $36^{\circ} \mathrm{C}$ to $-15^{\circ} \mathrm{C}$, while the ultimate tensile strain was not sensitive to the cryogenic service conditions. Therefore, the tensile properties of FRP determined at room temperature in this study might be slightly lower than those of FRP in the composite columns being tested under compression at $-3^{\circ} \mathrm{C}$. However, according to the existing studies (Nardone et al. 2012; Feng et al. 2016), such discrepancy is 
expected to be very limited due to the relatively small temperature range in this study. Therefore, the mechanical properties of LRS FRP, which were measured at room temperature in this study, can be considered as a simplified treatment slightly on the conservative side when they are used to analyze the composite stub columns.

\section{Test Setup and Instrumentation}

The experimental program was carried out in the structural testing laboratory at Dalian University of Technology in winter. Each specimen was tested with a 3,000 kN hydraulic servo testing machine via displacement control $(1.5 \mathrm{~mm} / \mathrm{min})$. The compression test was started when the indoor temperature was stabilized to around $-3^{\circ} \mathrm{C}$. Two square insulating plates were placed on each end of the test specimens to block thermal transmission (Wang et al. 2020b). Fig. 3(a) shows the test setup as well as the layout of the two linear variable displacement transducers (LVDTs). In addition, four pairs of strain gauges were bonded on the outer surface of LRS FRP tubes to obtain the axial and hoop strains. One of them was bonded at the center of the overlapping zone. Fig. 3(b) presents the location of the strain gauges.

\section{Results and Discussions}

\section{Failure Mode}

Fig. 4(a) presents the typical failure mode of the unconfined plain ice specimens at the ultimate state. A number of cracks developed in the axial direction, accompanied with significant dilation near the midheight region. However, as shown in Fig. 4(b), the unconfined sawdust-reinforced ice specimens experienced a very different failure mode compared with the unconfined plain ice specimens. Some wrinkles and a few short cracks were observed on the surface of the sawdust-reinforced ice specimens, which confirmed the advantageous effect caused by the incorporation of sawdust.

The failures of the IFFT specimens were similar to those of the SFFT specimens, characterized by the hoop rupture of the LRS FRP tubes (Fig. 5). The outer LRS FRP tubes in the confined ice specimens were cut off from the specimens after compression. It was observed that the inner ice dilated only behind the rupture regions of the external LRS FRP tubes. Some cracks developed within the vicinity of the rupture regions. Compared with the unconfined counterparts (Fig. 4), the lateral dilation of the inner ice was highly restrained by the LRS FRP confinement.

\section{Axial Load-Strain Curves for Specimens}

Fig. 6 shows the axial load-axial strain curves for the unconfined ice specimens. The axial loads of the unconfined ice specimens increased approximately linearly with increasing axial strains at the initial elastic stage. The elastic moduli of the unconfined ice with and without sawdust were calculated to be 0.28 and $0.36 \mathrm{GPa}$, respectively. The axial load-strain curves for the unconfined plain ice specimens entered the descending branches after reaching their peak points and experienced a rapid decline. By contrast, the axial loads of the unconfined sawdust-reinforced ice specimens decreased at a much slower rate, and the peak loads decreased by only $7.4 \%$ when the axial strain reached the value of 0.1 , which confirmed that the strength and especially the ductility of the plain ice could be substantially enhanced after introducing sawdust in ice. 
Fig. 7 shows the axial load-strain responses of the confined ice specimens. In order to make the figures more concise, the curves corresponding to three nominally identical specimens are presented by the same legend. The hoop strain was obtained based on the three hoop strain gauges outside the overlapping zone [Fig. 3(b)]. The axial load-strain responses of the confined ice specimens featured an approximately bilinear shape. The termination of the axial load-strain curves corresponded to the hoop rupture of the LRS FRP tubes. It was observed from Table 1 that the peak loads (denoted by $N_{e}$ ) of the confined ice specimens increased with the LRS FRP confinement. In addition, the bearing capacity of the SFFT specimens was larger than that of the IFFT specimens with the same tube thicknesses. The ratio of the maximum loads of the SFFT specimens to those of the IFFT specimens with the same confinement was denoted by $k$. The values of $k$ decreased with an increase of the number of the LRS FRP layers (Table 1).

\section{Axial Stress-Strain Curves for the Confined Ice}

The behavior of the confined ice can be well illustrated by its axial stress-strain responses. In the following discussions, compressive stresses and strains are considered positive in the confined ice, while tensile stresses and strains are considered positive in the outer LRS FRP tube. In traditional concrete-filled FRP tubes, the axial load carried by the outer FRP tube may be neglected owing to the much higher elastic modulus of concrete than that of FRP in the axial direction. However, the elastic modulus of ice is much smaller than that of concrete. Therefore, the axial bearing contribution of the outer LRS FRP tube was considered in this study, which was determined via a plane stress (hoop tension in combination with axial compression) analysis of the FRP tube (Li et al. 2018b; Xie 2018). The axial stress-strain responses of the inner ice are shown in Fig. 8. The axial stress of the confined ice was obtained by deducting the longitudinal contribution of the external LRS FRP tubes from the entire loads of the composite columns (Fig. 7) at the same axial strain. All curves approximately featured a monotonically ascending bilinear shape. A similar phenomenon was also observed in the axial compressive responses of conventional FRP-confined concrete stub columns (Xiao and Wu 2000; Lam and Teng 2003; Lin and Teng 2017; Cui and Sheikh 2010) and LRS FRP-confined concrete stub columns (Dai et al. 2011; Ispir 2015; Saleem et al. 2017; Bai et al. 2019; Pimanmas and Saleem 2019; Zeng et al. 2020a, b). Therefore, it might be a good way to establish the axial stress-strain models for the LRS FRPconfined ice on the basis of the theoretical models for FRP-confined concrete. In addition, a transition zone was observed in the axial stress-lateral strain curves for the confined ice when the lateral strain of the inner ice (denoted by $\varepsilon_{l}$ ) was equal to the negative turning strain of LRS FRP (i.e., $\varepsilon_{l}=-\varepsilon_{\text {frpo }}$ ), which should be captured when proposing a theoretical model for ice cores confined by LRS FRP jackets. The main test results, including the compressive strength, $f_{c c}^{\prime}$, the ultimate (also peak) axial

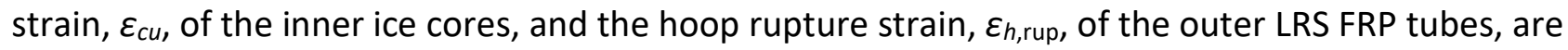
shown in Table 2. 
Table 2. Main experimental results of ice cores

\begin{tabular}{|c|c|c|c|c|c|c|c|c|c|c|}
\hline Series & Specimen & $\begin{array}{l}f_{c c}^{\prime} \\
(\mathrm{MPa})\end{array}$ & Average $f_{c c}^{\prime}(\mathrm{MPa})$ & $\frac{f_{c c}^{\prime}}{f_{c o}^{\prime}}$ & $\varepsilon_{c u}(\%)$ & Average $\varepsilon_{c u}(\%)$ & $\frac{\varepsilon_{c u}}{\varepsilon_{c o}}$ & $\varepsilon_{h, \text { rup }}(\%)$ & Average $\varepsilon_{h, \text { rup }}(\%)$ & $\frac{\varepsilon_{h, \text { rup }}}{\varepsilon_{f}}$ \\
\hline \multirow[t]{3}{*}{ IF1 } & IF1-I & 11.3 & 11.9 & 4.29 & 2.95 & 3.14 & 2.77 & 4.55 & 4.63 & 0.539 \\
\hline & IF1-II & 12.0 & & & 3.22 & & & 4.68 & & \\
\hline & IF1-III & 12.3 & & & 3.23 & & & 4.65 & & \\
\hline \multirow[t]{3}{*}{ SF1 } & SF1-I & 15.2 & 14.6 & 3.40 & 4.41 & 4.39 & 1.82 & 4.75 & 4.95 & 0.576 \\
\hline & SF1-II & 15.1 & & & 4.84 & & & 5.02 & & \\
\hline & SF1-III & 13.4 & & & 3.92 & & & 5.08 & & \\
\hline \multirow[t]{3}{*}{ IF2 } & IF2-I & 15.7 & 16.9 & 6.09 & 4.11 & 4.18 & 3.70 & 4.38 & 4.54 & 0.529 \\
\hline & IF2-II & 17.7 & & & 4.18 & & & 4.56 & & \\
\hline & IF2-III & 17.2 & & & 4.26 & & & 4.68 & & \\
\hline \multirow[t]{3}{*}{ SF2 } & SF2-I & 20.1 & 19.8 & 4.61 & 5.28 & 5.41 & 2.25 & 5.07 & 5.14 & 0.598 \\
\hline & SF2-II & 19.0 & & & 5.36 & & & 5.01 & & \\
\hline & SF2-III & 20.2 & & & 5.60 & & & 5.33 & & \\
\hline \multirow[t]{3}{*}{ IF3 } & IF3-I & 24.8 & 24.9 & 8.97 & 5.33 & 5.34 & 4.72 & 4.43 & 4.49 & 0.523 \\
\hline & IF3-II & 24.0 & & & 5.29 & & & 4.55 & & \\
\hline & IF3-III & 25.8 & & & 5.39 & & & 4.49 & & \\
\hline \multirow[t]{3}{*}{ SF3 } & SF3-I & 26.7 & 25.9 & 6.04 & 6.53 & 6.30 & 2.61 & 5.20 & 5.01 & 0.583 \\
\hline & SF3-II & 24.7 & & & 6.25 & & & 5.03 & & \\
\hline & SF3-III & 26.2 & & & 6.11 & & & 4.80 & & \\
\hline
\end{tabular}

Note: $f_{c o}^{\prime}$ and $\varepsilon_{c o}=$ compressive strength and the corresponding axial strain of the unconfined ice at the peak point $(2.8 \mathrm{MPa}$ and $1.13 \%$ for ice without sawdust, whereas $4.3 \mathrm{MPa}$ and $2.41 \%$ for ice with sawdust). 
The initial elastic moduli of the LRS FRP-confined ice with and without sawdust were 0.59 and 0.83 GPa, which were calculated from Fig. 8 and higher than those of the corresponding unconfined counterparts. However, the initial slope of the stress-strain model for FRP-confined concrete proposed by Lam and Teng (2003) was believed to be identical to the elastic modulus of unconfined concrete. The different observations might be mainly attributed to the different Poisson's ratios of the two materials. Based on the results reported in the existing literature works, Poisson's ratio of ice is around 0.3 (Gammon et al. 1983; Sinha 1989; Staroszczyk 2019), which is larger than that of the concrete (around 0.2). The larger Poisson's ratio caused ice to dilate more severely than concrete at a given axial strain during the initial loading stage. Therefore, the FRP confinement in the FRP-confined ice columns was activated much earlier than that in the FRP-confined concrete columns, leading to a higher initial elastic modulus of the FRP-confined ice than that of the corresponding unconfined counterpart. An increase in the initial modulus from unconfined ice to confined ice was also observed in the triaxial compression test conducted by Shan et al. (2017) on cylindrical ice specimens.

It can be observed from Table 2 that the sawdust-reinforced ice cores had larger $f_{c c}^{\prime}$ and $\varepsilon_{c u}$ than the plain ice cores with the same confinement. Moreover, the values of $f_{c c}^{\prime}$ and $\varepsilon_{c u}$ of the inner ice increased with the LRS FRP confinement. In summary, it revealed that the compressive behavior of the inner ice can be substantially improved by sawdust and LRS FRP confinement. Besides, the value of $\varepsilon_{h, \text { rup }} / \varepsilon_{f}$ in SFFT was greater than that in IFFT with the same confinement, which indicated that the inclusion of sawdust in ice cylinders leads to a higher efficiency factor of the LRS FRP jacket. As shown in Table 2, it should be admitted that the effect of FRP confinement on the compressive behavior of plain ice is much more significant than that of the inclusion of sawdust in ice. However, the sawdust has other functions in addition to improving the engineering properties of ice. First, the introduction of sawdust into ice is beneficial to slow down its creep rate (Vasiliev et al. 2015) as well as melting rate (Wang et al. 2020c). In addition, if part of the volume of the ice is replaced by a nonfrozen material (such as sawdust), the ice will freeze faster (Makkonen 1994), thereby speeding up the hardening of the ice column and saving time in the construction of the ice structure. Therefore, it is recommended to introduce sawdust into the ice, although the LRS FRP confinement for sawdust-reinforced ice is not as effective as that for plain ice.

The axial compressive behavior of plain ice cylinders confined by GFRP was investigated by Wang et al. (2020b). According to the tensile tests, the GFRP with a nominal thickness of $0.157 \mathrm{~mm}$ per ply had higher elastic modulus (i.e., 72.2 GPa) but lower stain capacity (i.e., 2.48\%) than those of the LRS FRP. The value of $f_{c c}^{\prime} / f_{c o}^{\prime}$ of the LRS FRP-confined plain ice was approximately twice as large as that of GFRPconfined ice, corresponding to an approximately equal confinement level. Moreover, the average value of $\varepsilon_{c u} / \varepsilon_{c o}$ of the GFRP-confined ice (around 2.70\%) was less affected by the increasing GFRP confinement, which was much smaller than the test results of the LRS FRP-confined plain ice (Table 2). Therefore, the compressive strength and the ultimate axial strain of the plain ice can be more effectively improved by the LRS FRP tube than by the GFRP tube at the same confinement level.

\section{Dilation Properties}

Fig. 9 shows the lateral strain-axial strain curves for the LRS FRP-confined ice. A close trend was observed for all curves, corresponding to a small axial strain level (less than $0.5 \%$ ). Afterward, the lateral strains of confined ice increased at a faster rate with the development of the axial strain. As 
expected, the lateral strains of the ice cores confined by an LRS tube with more FRP layers were smaller at a given axial strain, which confirmed that a better confinement effect could be achieved when a thicker LRS FRP tube was used. Moreover, at a given axial strain, the sawdust-reinforced ice cores had smaller lateral strains than the plain ice cores with the same LRS confinement, which revealed that the dilation of the inner ice could be greatly restrained by the sawdust bridging effect (Wang et al. 2020c). Unfortunately, the dilation properties of unconfined ice were not obtained due to the great difficulty in installing strain gauges on the surface of ice.

The interactions between the outer LRS FRP tubes and the ice cores could be reflected by the dilation models (i.e., lateral strain-axial strain relation) for confined ice. The overall trend of the lateral strainaxial strain responses of the inner ice in this study is similar to that of FRP-confined concrete.

Consequently, it is reasonable to develop a dilation model for the LRS FRP-confined ice on the basis of the existing dilation models proposed for concrete cylinders confined by FRP jackets. In other words, a theoretical analysis on FRP-confined concrete might also be applicable for confined ice when ice is treated as a kind of weak concrete (Wang et al. 2020b).

The dilation model for conventional FRP-confined concrete, initially developed by Teng et al. (2007), is involved in the analysis-oriented model of Jiang and Teng (2007)

(2)

$$
\frac{\varepsilon_{c}}{\varepsilon_{c o}}=A\left(\alpha+\beta \frac{\sigma_{l}}{f_{c o}^{\prime}}\right)\left\{\left[1+B\left(\frac{-\varepsilon_{l}}{\varepsilon_{c o}}\right)\right]^{C}-\exp \left[D\left(\frac{-\varepsilon_{l}}{\varepsilon_{c o}}\right)\right]\right\}
$$

$$
\sigma_{l}=\frac{2 \sigma_{h} t}{D}
$$

where $f_{c o}^{\prime}$ and $\varepsilon_{c o}=$ compressive strength and corresponding axial strain of the unconfined concrete, respectively; $A=0.85, B=0.75, C=0.7, D=-7, \alpha=1, b=8$ for the FRP-confined concrete analyzed by Teng et al. (2007); $\sigma_{l}=$ confining pressure; $t=$ nominal thickness of the LRS FRP tube; $D=$ diameter of the concrete core; and $\sigma_{h}=$ hoop tensile stress of the LRS FRP tube, and its values can be obtained by taking $\varepsilon_{\text {frp }}=-\varepsilon$, into Eq. (1). According to the dilation model developed by Teng et al. (2007), the predicted lateral strain-axial strain response of the plain ice wrapped by 1-ply LRS FRP using Eq. (2) is shown in Fig. 9, which indicates that the dilation of the inner ice is severely underestimated. The discrepancy reveals that ice tends to dilate more quickly than concrete under compression. Therefore, the framework of the dilation model developed by Teng et al. (2007) needs to be adjusted, and some of the coefficients in Eq. (2) need to be recalibrated by the available test results.

In accordance with Teng et al. (2007), the lateral stain-axial strain relation of the FRP-confined concrete is given as follows:

(4)

$$
\frac{\varepsilon_{c}}{\varepsilon_{c o}}=f\left(\frac{-\varepsilon_{l}}{\varepsilon_{c o}}\right)\left(\alpha+\beta \frac{\sigma_{l}}{f_{c o}^{\prime}}\right)
$$


where the value of $\alpha$ is equal to one to satisfy the boundary condition without confinement. In order to satisfy the same boundary condition requirement, $\alpha$ should also be one for confined ice. However, the value of $B$ should be recalibrated by the experimental results related to confined ice. By setting $\alpha=1$, Eq. (4) can be rewritten as follows:

$$
f\left(\frac{-\varepsilon_{l}}{\varepsilon_{c o}}\right)=\frac{\frac{\varepsilon_{c}}{\varepsilon_{c o}}}{1+\beta \frac{\sigma_{l}}{f_{c o}^{\prime}}}
$$

where the right side of the equation can be considered as equivalent normalized axial strain (Dai et al. 2011).

According to the experimental results of axially loaded LRS FRP-confined concrete cylinders, Dai et al. (2011) developed a simpler lateral strain equation as follows:

$$
f\left(\frac{-\varepsilon_{l}}{\varepsilon_{c o}}\right)=a\left(\frac{-\varepsilon_{l}}{\varepsilon_{c o}}\right)^{b}+c\left(\frac{-\varepsilon_{l}}{\varepsilon_{c o}}\right)
$$

where $a=1.024, b=0.350$, and $c=0.089$ were deduced from their test results. The predicted lateral strain-axial strain curve of the plain ice wrapped by 1-ply LRS FRP using Eqs. (5) and (6) is shown in Fig. 9, which indicates that the calculated result by Eq. (6) is little more accurate than that obtained using Eq. (2) when predicting the dilation properties of confined ice. However, the dilation of confined ice is still severely underestimated. Therefore, the values of coefficients in Eq. (6) including $a, b$, and $c$ need to be recalibrated.

In LRS-confined concrete, the value of $c$ is much smaller than those of $a$ and $b$. Consequently, the value of $c$ was assumed to be zero in this study for simplification. Therefore, the dilation model for the LRS FRP-confined ice was assumed as follows:

$$
\frac{\varepsilon_{c}}{\varepsilon_{c o}}=a\left(\frac{-\varepsilon_{l}}{\varepsilon_{c o}}\right)^{b}\left(1+\beta \frac{\sigma_{l}}{f_{c o}^{\prime}}\right)
$$

where $B=0.2$ was obtained via trial and error. Fig. 10 exhibits the relationship between the equivalent normalized axial strain and the normalized lateral strain of the confined ice. Based on regression analysis, $a=1.08$ and $b=0.48$ were obtained for the LRS FRP-confined plain ice, while $a=1.11$ and $b=$ 0.46 were obtained for the LRS FRP-confined sawdust-reinforced ice. Therefore, the dilation model for the LRS FRP-confined ice in this study was given by 


$$
\frac{\varepsilon_{c}}{\varepsilon_{c o}}= \begin{cases}1.08\left(1+0.2 \frac{\sigma_{l}}{f_{c o}^{\prime}}\right)\left(\frac{-\varepsilon_{l}}{\varepsilon_{c o}}\right)^{0.48} & \text { forIFFT } \\ 1.11\left(1+0.2 \frac{\sigma_{l}}{f_{c o}^{\prime}}\right)\left(\frac{-\varepsilon_{l}}{\varepsilon_{c o}}\right)^{0.46} & \text { forSIFFT }\end{cases}
$$

Transition Stress and Transition Strain

As shown in Fig. 8, an obvious softening trend was observed in the axial stress-lateral strain responses of the confined ice when $\varepsilon_{l}=-\varepsilon_{\text {frpo. }}$. Meanwhile, a transition zone occurred in the corresponding axial stress-axial strain responses of the inner ice. Taking the plain ice core in IFFT Specimen IF2-III as an example, the determinations of transition stress and transition strain of confined ice are shown in Fig. 11. First, a vertical straight line was drawn at $\varepsilon_{l}=-\varepsilon_{\text {frpo }}$ to intersect the axial stress-lateral strain curve at Point $A$. Next, one horizontal line passing Point $A$ was drawn to intersect the axial stress-axial strain responses of the inner ice at Point $B$. Finally, the abscissa and ordinate of Point $B$ were defined as the transition strain, $\varepsilon_{t}$, and the transition stress, $\sigma_{t}$, of the ice cores in this study, respectively.

According to this definition, the values of transition strain, $\varepsilon_{t}$, can be determined by taking $\varepsilon_{l}=-\varepsilon_{\text {frpo }}$ into Eq. (8), which is given by

$$
\frac{\varepsilon_{t}}{\varepsilon_{c o}}= \begin{cases}1.08\left[1+0.2 \frac{\sigma_{l}\left(\varepsilon_{\mathrm{frp} 0}\right)}{f_{c o}^{\prime}}\right]\left(\frac{\varepsilon_{\mathrm{frp} 0}}{\varepsilon_{c o}}\right)^{0.48} & \text { forIFFT } \\ 1.11\left[1+0.2 \frac{\sigma_{l}\left(\varepsilon_{\mathrm{frp} 0}\right)}{f_{c o}^{\prime}}\right]\left(\frac{\varepsilon_{\mathrm{frp} 0}}{\varepsilon_{c o}}\right)^{0.46} & \text { forSIFFT }\end{cases}
$$

where $\sigma_{l}\left(\varepsilon_{\mathrm{frpo}}\right)$ is the confining stress of the LRS FRP tube to the ice core when the hoop tensile strain, $\varepsilon_{h}$, of the LRS FRP tube equals the material turning strain, $\varepsilon_{\mathrm{frpo}}$, from the flat coupon tests, which is determined by

$$
\sigma_{l}\left(\varepsilon_{\mathrm{frp} 0}\right)=\frac{2 E_{\mathrm{frp} 1} \varepsilon_{\mathrm{frp} 0} t}{D}
$$

The relationship between the transition stress, $\sigma_{t}$, of the confined ice and the corresponding confining stress, $\sigma_{l}\left(\varepsilon_{\mathrm{frpo}}\right)$, is presented in Fig. 12. Based on the approximately linear relationship between $\sigma_{t}$ and $\sigma_{l}\left(\varepsilon_{\mathrm{frpo}}\right)$, an equation was proposed to determine the transition stress, $\sigma_{t}$, of the confined ice

$$
\frac{\sigma_{t}}{f_{c o}^{\prime}}= \begin{cases}2.16+1.04 \frac{\sigma_{l}\left(\varepsilon_{\mathrm{frp} 0}\right)}{f_{c o}^{\prime}} & \text { forIFFT } \\ 1.39+1.13 \frac{\sigma_{l}\left(\varepsilon_{\mathrm{frp} 0}\right)}{f_{c o}^{\prime}} & \text { forSIFFT }\end{cases}
$$




\section{Second Stiffness}

The axial stress-axial strain responses of the inner ice were divided by the transition point into two branches. The slope of the second portion with a highly linear shape was defined as the second stiffness, $E_{2}$, of the confined ice. Considering that the curves for the inner ice (Fig. 8) exhibited similar shapes to those of FRP-confined concrete, ice might be treated as a kind of weak concrete. Therefore, some research findings related to FRP-confined concrete were adopted as a reference during the theoretical analysis of $E_{2}$ of the inner ice in this study.

For FRP-confined concrete, an important parameter termed as confinement stiffness ratio, $\rho_{K}$, was defined by Teng et al. (2009), which reflected the ratio of the FRP jacket's confinement stiffness to concrete's secant modulus at the peak point

$$
\rho_{K}=\frac{2 E_{\mathrm{frp}} t}{\left(f_{c o}^{\prime} / \varepsilon_{c o}\right) D}
$$

where $f_{c o}^{\prime}$ and $\varepsilon_{c o}=$ peak stress and the corresponding axial strain of the unconfined concrete, respectively; $E_{\mathrm{frp}}=$ elastic modulus of FRP tubes; $t=$ thickness of FRP tubes corresponding to $E_{\mathrm{frp}}$; and $D$ $=$ diameter of concrete core.

Converted from the original expressions of $\rho_{\kappa}$, another parameter termed as confinement rigidity, $\rho$, was defined by Li and Wu (2015):

$$
\rho=\frac{2 E_{\mathrm{frp}} t}{D f_{c o}^{\prime}}
$$

Compared with the definition of the confinement stiffness ratio, $\rho_{K}$, the only difference in the expression of confinement rigidity, $\rho$, is that $\varepsilon_{c o}$ has been omitted. Considering that the values of $\varepsilon_{c o}$ of unconfined normal concrete is generally stabilized at around 0.002 , it may be more concise to evaluate the second stiffness of FRP-confined concrete using confinement rigidity, $\rho$. The second stiffness of the inner concrete-confined conventional FRP as well as and LRS FRP jackets was predicted by Li et al. (2018a) and Bai et al. (2019) as follows:

$$
\frac{E_{2}}{f_{c o}^{\prime}}=m \rho^{n}+q
$$

where $m, n$, and $q$ are the coefficients to be determined.

The average $\varepsilon_{c o}$ of the unconfined plain ice (i.e., 1.13\%) is much smaller than that of the unconfined sawdust-reinforced ice (i.e., $2.41 \%$ ) in this study. Furthermore, the peak axial strain, $\varepsilon_{c o}$, of the unconfined sawdust-reinforced ice may vary significantly corresponding to different weight ratios of the sawdust introduced. Therefore, in the present study, $\rho$ was replaced by $\rho_{K}$ in Eq. (14) to better evaluate the discrepancies between the material properties of the unconfined ice with different contents of the reinforcing agent. Additionally, it is worth mentioning that the second elastic modulus, 
$E_{\text {frp2, }}$ of LRS FRP was used during the determination of $\rho_{k}$ using Eq. (12) because the hoop tensile strain of the LRS FRP jacket had exceeded the material turning strain, $\varepsilon_{\mathrm{frp} 0}$, of LRS FRP determined via flat coupon tests at the current stage.

The values of the three coefficients need to be discussed previously the regression analysis. Fig. 13 presents the influence of the confinement stiffness ratio, $\rho_{k}$, on the second stiffness, $E_{2}$, of the confined ice. It was observed that the second stiffness increased with the confinement stiffness ratio, which required that the values of $m$ and $n$ had the same positive or negative signs. On the other hand, it is impossible for $E_{2}$ to increase indefinitely with increasing $\rho_{K}$. In other words, it is believed that there is an upper boundary for the value of $E_{2}$, which requires that the values of both $m$ and $n$ are negative. In this study, the initial elastic modulus, $E_{c}$, of the confined ice was considered as the upper boundary of the second stiffness of ice cores because the initial elastic modulus is generally the largest modulus of an engineering material. Therefore, the value of $q$ was assumed to be equal to $E_{c} / f_{c o}^{\prime}$.

As shown in Fig. 13, regression analysis was carried out after careful discussions on the values of three coefficients. The experimental value of $E_{2}$ from Specimen IF2-I was far smaller than those of other specimens within the same group, which was excluded during the regression analysis. Finally, the following equation was developed by regression analysis to evaluate the second stiffness, $E_{2}$, of the LRS FRP-confined ice:

$$
\frac{E_{2}}{f_{c o}^{\prime}}= \begin{cases}-184.98 \rho_{K}^{-0.2}+\frac{E_{c}}{f_{c o}^{\prime}} & \text { forIFFT } \\ -72.04 \rho_{K}^{-0.18}+\frac{E_{c}}{f_{c o}^{\prime}} & \text { forSIFFT }\end{cases}
$$

\section{Proposed Model for Confined Ice}

\section{Equations of the Proposed Model}

In order to achieve a more reliable design of the proposed IFFT and SFFT columns, a good stress-strain model for the LRS FRP-confined ice remains to be established. Overall, the axial stress-strain responses of the inner ice in this study behaved similar to those of FRP-confined concrete. Therefore, the FRPconfined concrete model was introduced as a reference during the establishment of the theoretical model for the confined ice. The proposed theoretical model for the inner ice is illustrated in Fig. 14, which captures all the main features of the compressive behavior of the ice cores confined by the LRS FRP tubes. Similar to the model of Lam and Teng (2003) for concrete cylinders wrapped by conventional FRP jackets, the proposed axial stress-axial strain model for the LRS FRP-confined ice also consists of two branches.

The first branch of the theoretical model for the confined ice is assumed to be a parabolic curve expressed as a quadratic equation. It is solely determined by the three boundary conditions as follows: (1) passing the origin; (2) the derivative at the origin being identical to the compressive elastic modulus, $E_{c}$, of the confined ice; and (3) passing the transition point $\left(\varepsilon_{t}, \sigma_{t}\right)$. 
The second branch of the theoretical model for the confined ice is expressed as a linear equation. It is solely determined by the two boundary conditions as follows: (1) passing the transition point $\left(\varepsilon_{t}, \sigma_{t}\right)$; and (2) the right-hand derivative at the transition point being equal to the second stiffness, $E_{2}$, of the confined ice.

Finally, the full-range axial stress-axial strain curve of the inner ice can be determined by Eq. (16). The overall framework is consistent with the FRP-confined concrete model proposed by Wei and Wu (2012). However, there are obvious distinctions between the two models in the calculation of parameters including $\varepsilon_{t}, \sigma_{t}$, and $E_{2}$.

$$
\sigma_{c}=\left\{\begin{array}{cc}
E_{c} \varepsilon_{c}+\frac{\sigma_{t}-E_{c} \varepsilon_{t}}{\varepsilon_{t}^{2}} \varepsilon_{c}^{2}, & 0 \leq \varepsilon_{c} \leq \varepsilon_{t} \\
\sigma_{t}+E_{2}\left(\varepsilon_{c}-\varepsilon_{t}\right), & \varepsilon_{t} \leq \varepsilon_{c} \leq \varepsilon_{c u}
\end{array}\right.
$$

where $\sigma_{c}$ and $\varepsilon_{c}=$ axial stress and strain of the confined ice, respectively; $E_{c}=$ initial elastic modulus of the confined ice, with average values of $0.83 \mathrm{GPa}$ for the confined plain ice and $0.59 \mathrm{GPa}$ for the confined sawdust-reinforced ice in this study; $\sigma_{t}$ and $\varepsilon_{t}=$ transition stress and strain of the confined ice, respectively; $E_{2}=$ second stiffness of the confined ice, which is determined by Eq. (15); and $\varepsilon_{c u}=$ the ultimate (also peak) axial strain of the confined ice, which is determined by taking $\varepsilon_{l}=-\varepsilon_{h \text {,rup into Eq. }}$. (8).

\section{Evaluation of the Proposed Model}

On the basis of the proposed model for the LRS FRP-confined ice, Fig. 8 presents the calculated axial stress-strain curves for the inner ice with and without sawdust. The hoop rupture strains, $\varepsilon_{h \text {,rup, of the }}$ LRS FRP tubes were taken as the average values of the three nominally identical specimens within the same group. It can be observed from Fig. 8 that the predicted curves are close to the experimental results, which indicates that the compressive behavior of the confined ice can be accurately predicted by the theoretical model.

To further evaluate the performance of the proposed model, Fig. 15 compares the predictions of the theoretical model with the experimental results at the ultimate condition. The ultimate axial strain, $\varepsilon_{c u}$

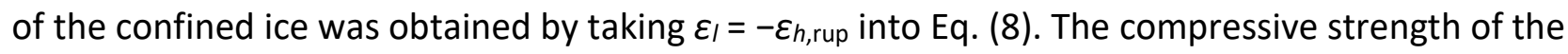
confined ice was determined by taking $\varepsilon_{c}=\varepsilon_{c u}$ into Eq. (16). It can be observed from Fig. 15 that the peak stress and the corresponding axial strain of the confined ice can be well evaluated with reasonable accuracy.

It should be admitted that the theoretical model for the LRS FRP-confined ice was established mainly based on the experimental results of this study. There are currently no other experimental data available as per the authors' best knowledge. If more data are available, the model may be modified. Furthermore, it should be clearly pointed out that the findings of this work and the proposed model are for short-term properties. It is well known that ice will creep under a sustained load (Duval et al. 1983; Ashby and Duval 1985; Schulson and Duval 2009). If the proposed stub column is subjected to a long-term sustained load, the stress redistribution is expected to occur between the outer FRP tube and the inner ice over time mainly due to the creep of ice. The confinement effectiveness of the LRS 
FRP tube may also be weakened by an increase of the axial load on the tube caused by the creep of the inner ice. Consequently, the change of the interaction between the two parts may cause the stressstrain response of the LRS FRP-confined ice to be different. Therefore, more experimental investigations into the composite columns under both short-term and long-term loads need to be carried out. The stress-strain model for the LRS FRP-confined ice in this study can be recalibrated and refined in the future study based on more experimental results. In addition, the temperature of ice is also an important variable. The elastic modulus and the compressive and tensile strengths of ice tend to increase with the decrease of temperature from $0^{\circ} \mathrm{C}$ to $-40^{\circ} \mathrm{C}$ (Schulson 2001; Petrovic 2003; Schulson and Duval 2009). The effect of temperature on ice strength is more prominent in compression than that in tension (Petrovic 2003). Moreover, the creep rate of ice reduces with the decrease of temperature from $0^{\circ} \mathrm{C}$ to $-60^{\circ} \mathrm{C}$ (Mellor and Testa 1969). Therefore, the effect of temperature should also be considered in the development of the model for the LRS FRP-confined ice in the future. Finally, a series of other factors (e.g., additional reinforcement, loading rate, bending moment, and ice melting) will be further studied in the future.

\section{Conclusions}

In this paper, an experimental study on the axial compressive behavior of ice cylinders with and without sawdust confined by circular LRS FRP tubes was presented. The following conclusions can be drawn on the basis of the experimental results and theoretical discussions:

1. Compared with the failure of the unconfined plain ice characterized by many longitudinal cracks developing along the whole height, both types of circular IFFT and SFFT stub columns failed by the circumferential rupture of the outer LRS FRP tube. The dilation of the cracked ice cylinders was greatly restrained by the LRS FRP confinement.

2. The axial stress-strain curves for LRS FRP-confined ice cylinders with and without sawdust exhibited an approximately bilinear shape. The peak stress and the corresponding axial strain of the inner ice were increased by the LRS FRP confinement as well as the incorporation of sawdust.

3. The dilation models for FRP-confined concrete should not be directly adopted in the LRS FRP-confined ice as they underestimated the lateral strain of the latter at a given axial strain, while the recalibrated model provided a good evaluation of the dilation property of the LRS FRP-confined ice.

4. A theoretical model consisting of a first parabolic branch followed by a second linear part was proposed to describe the entire stress-strain response of the LRS FRP-confined ice cores. The evaluation through the theoretical model had a reasonably close agreement with experimental results.

\section{Data Availability Statement}

Some or all data, models, or code generated or used during the study are available from the corresponding author by request. They include all original data obtained from the experimental tests. 


\section{Acknowledgments}

The authors are grateful for financial support from the National Key R\&D Program of China (2017YFC0703000), the National Natural Science Foundation of China (51778102 and 51978126), the Fundamental Research Funds for the Central Universities of China (DUT18LK35), and the Natural Science Foundation of Liaoning Province of China (20180550763).

\section{References}

Ashby, M. F., and P. Duval. 1985. "The creep of polycrystalline ice." Cold Reg. Sci. Technol. 11 (3): 285300. https://0-doi-org.libus.csd.mu.edu/10.1016/0165-232X(85)90052-7.

ASTM. 2017. Standard test method for tensile properties of polymer matrix composites materials. ASTM D3039/D3039M-17. West Conshohocken, PA: ASTM.

Bai, Y. L., J. G. Dai, M. Mohammadi, G. Lin, and S. J. Mei. 2019. "Stiffness-based design-oriented compressive stress-strain model for large-rupture-strain (LRS) FRP-confined concrete." Compos. Struct. 223: 110953. https://0-doiorg.libus.csd.mu.edu/10.1016/j.compstruct.2019.110953.

Bai, Y. L., Z. W. Yan, T. Ozbakkaloglu, Q. Han, J. G. Dai, and D. J. Zhu. 2020. "Quasi-static and dynamic tensile properties of large-rupture-strain (LRS) polyethylene terephthalate fiber bundle." Constr. Build. Mater. 232: 117241. https://0-doiorg.libus.csd.mu.edu/10.1016/j.conbuildmat.2019.117241.

Cao, Q., H. Li, and Z. Lin. 2020. "Effect of active confinement on compressive behavior of glass fiberreinforced polymer-confined e

old Reg. Sci. Technol. 11 (3): 285-300. https://0-doi-org.libus.csd.mu.edu/10.1016/0165232X(85)90052-7.

ASTM. 2017. Standard test method for tensile properties of polymer matrix composites materials. ASTM D3039/D3039M-17. West Conshohocken, PA: ASTM.

Bai, Y. L., J. G. Dai, M. Mohammadi, G. Lin, and S. J. Mei. 2019. "Stiffness-based design-oriented compressive stress-strain model for large-rupture-strain (LRS) FRP-confined concrete." Compos. Struct. 223: 110953. https://0-doiorg.libus.csd.mu.edu/10.1016/j.compstruct.2019.110953.

Bai, Y. L., Z. W. Yan, T. Ozbakkaloglu, Q. Han, J. G. Dai, and D. J. Zhu. 2020. “Quasi-static and dynamic tensile properties of large-rupture-strain (LRS) polyethylene terephthalate fiber bundle." Constr. Build. Mater. 232: 117241. https://0-doiorg.libus.csd.mu.edu/10.1016/j.conbuildmat.2019.117241.

Cao, Q., H. Li, and Z. Lin. 2020. "Effect of active confinement on compressive behavior of glass fiberreinforced polymer-confined expansive concrete under axial cyclic loading." ACI Struct. J. 117 (1): 207-216. https://0-doi-org.libus.csd.mu.edu/10.14359/51718074.

Cao, Q., J. Tao, Z. Wu, and Z. J. Ma. 2017. "Behavior of FRP-steel confined concrete tubular columns made of expansive self-consolidating concrete under axial compression." J. Compos. Constr. 21 (5): 04017037. https://0-doi-org.libus.csd.mu.edu/10.1061/(ASCE)CC.1943-5614.0000818.

Cui, C., and S. A. Sheikh. 2010. "Experimental study of normal- and high-strength concrete confined with fiber-reinforced polymers." J. Compos. Constr. 14 (5): 553-561. https://0-doiorg.libus.csd.mu.edu/10.1061/(ASCE)CC.1943-5614.0000116. 
Dai, J. G., Y. L. Bai, and J. G. Teng. 2011. "Behavior and modeling of concrete confined with FRP composites of large deformability." J. Compos. Constr. 15 (6): 963-973. https://0-doiorg.libus.csd.mu.edu/10.1061/(ASCE)CC.1943-5614.0000230.

Dewar, K., D. Meyer, and W. M. Li. 2001. "Harbin, lanterns of ice, sculptures of snow." Tourism Manage. 22 (5): 523-532. https://0-doi-org.libus.csd.mu.edu/10.1016/S0261-5177(01)00007-3.

Duval, P., M. F. Ashby, and I. Anderman. 1983. "Rate-controlling processes in the creep of polycrystalline ice." J. Phys. Chem. 87 (21): 4066-4074. https://0-doiorg.libus.csd.mu.edu/10.1021/j100244a014.

Fam, A. Z., and S. H. Rizkalla. 2001. "Behavior of axially loaded concrete-filled circular fiber-reinforced polymer tubes." ACI Struct. J. 98 (3): 280-289. https://0-doiorg.libus.csd.mu.edu/10.14359/10217.

Feng, P., J. Wang, Y. Tian, D. Loughery, and Y. Wang. 2016. "Mechanical behavior and design of FRP structural members at high and low service temperatures." J. Compos. Constr. 20 (5): 04016021. https://0-doi-org.libus.csd.mu.edu/10.1061/(ASCE)CC.1943-5614.0000676.

Gammon, P. H., H. Kiefte, M. J. Clouter, and W. W. Denner. 1983. "Elastic constants of artificial and natural ice samples by Brillouin spectroscopy." J. Glaciol. 29 (103): 433-460. https://0-doiorg.libus.csd.mu.edu/10.1017/S0022143000030355.

Gold, L. W. 1977. “Engineering properties of fresh-water ice.” J. Glaciol. 19 (81): 197-212. https://0doi-org.libus.csd.mu.edu/10.3189/S0022143000215608.

Iliescu, D., and E. M. Schulson. 2002. "Brittle compressive failure of ice: Monotonic versus cyclic loading." Acta Mater. 50 (8): 2163-2172. https://0-doi-org.libus.csd.mu.edu/10.1016/S13596454(02)00060-5.

Ispir, M. 2015. "Monotonic and cyclic compression tests on concrete confined with PET-FRP." J. Compos. Constr. 19 (1): 04014034 . https://0-doi-org.libus.csd.mu.edu/10.1061/(ASCE)CC.19435614.0000490.

Jiang, T., and J. G. Teng. 2007. "Analysis-oriented stress-strain models for FRP-confined concrete." Eng. Struct. 29 (11): 2968-2986. https://0-doi-

org.libus.csd.mu.edu/10.1016/j.engstruct.2007.01.010.

Lam, L., and J. G. Teng. 2003. "Design-oriented stress-strain model for FRP-confined concrete." Constr. Build. Mater. 17 (6-7): 471-489. https://0-doi-org.libus.csd.mu.edu/10.1016/S09500618(03)00045-X.

Lechat, C., A. R. Bunsell, and P. Davies. 2011. "Tensile and creep behavior of polyethylene terephthalate and polyethylene naphthalate fibres." J. Mater. Sci. 46 (2): 528-533. https://0doi-org.libus.csd.mu.edu/10.1007/s10853-010-4999-x.

Li, J., J. Xie, F. Liu, and Z. Lu. 2019. "A critical review and assessment for FRP-concrete bond systems with epoxy resin exposed to chloride environments." Compos. Struct. 229: 111372. https://0doi-org.libus.csd.mu.edu/10.1016/j.compstruct.2019.111372.

Li, J. H., Z. Wei, and C. Wu. 2015. "Preparation and properties of novel building materials at low temperature." Mater. Des. 67: 464-468. https://0-doi-

org.libus.csd.mu.edu/10.1016/j.matdes.2014.10.040.

Li, P., and Y. F. Wu. 2015. "Stress-strain model of FRP confined concrete under cyclic loading." Compos. Struct. 134: 60-71. https://0-doi-org.libus.csd.mu.edu/10.1016/j.compstruct.2015.08.056. 
Li, P., Y. F. Wu, Y. Zhou, and F. Xing. 2018a. "Cyclic stress-strain model for FRP-confined concrete considering post-peak softening." Compos. Struct. 201: 902-915. https://0-doiorg.libus.csd.mu.edu/10.1016/j.compstruct.2018.06.088.

Li, Y. L., J. G. Teng, X. L. Zhao, and R. K. S. Raman. 2018b. "Theoretical model for seawater and sea sand concrete-filled circular FRP tubular stub columns under axial compression." Eng. Struct. 160: 71-84. https://0-doi-org.libus.csd.mu.edu/10.1016/j.engstruct.2018.01.017.

Lin, G., and J. G. Teng. 2017. "Three-dimensional finite-element analysis of FRP-confined circular concrete columns under eccentric loading." J. Compos. Constr. 21 (4): 04017003. https://0-doiorg.libus.csd.mu.edu/10.1061/(ASCE)CC.1943-5614.0000772.

Makkonen, L. 1994. Ice and construction. London: E \& FN Spon.

Masterson, D. M. 2009. "State of the art of ice bearing capacity and ice construction." Cold Reg. Sci. Technol. 58 (3): 99-112. https://0-doi-org.libus.csd.mu.edu/10.1016/j.coldregions.2009.04.002.

Mellor, M., and R. Testa. 1969. “Effect of temperature on the creep of ice.” J. Glaciol. 8 (52): 131-145. https://0-doi-org.libus.csd.mu.edu/10.1017/S0022143000020803.

Mesher, D., and S. Proskin. 2008. "Ice road assessment, modeling and management." In 7th Int. Conf. on Managing Pavement Assets, Calgary. Alberta, Canada: Transportation Research Board Committee.

Michel, B., M. Drouin, L. M. Lefebvre, P. Rosenberg, and R. Murray. 1974. "Ice bridges of the James Bay Project." Can. Geotech. J. 11 (4): 599-619. https://0-doi-org.libus.csd.mu.edu/10.1139/t74-060.

Mohamed, H. M., and R. Masmoudi. 2010. "Axial load capacity of concrete-filled FRP tube columns: Experimental versus theoretical predictions." J. Compos. Constr. 14 (2): 231-243. https://0-doiorg.libus.csd.mu.edu/10.1061/(ASCE)CC.1943-5614.0000066.

Nardone, F., M. Di Ludovico, F. J. De Caso y Basalo, A. Prota, and A. Nanni. 2012. "Tensile behavior of epoxy based FRP composites under extreme service conditions." Composites, Part B 43 (3): 1468-1474. https://0-doi-org.libus.csd.mu.edu/10.1016/j.compositesb.2011.08.042.

Nixon, W. A. 1989. "Alluvium-reinforced ice: A preliminary report of bending strength tests." Cold Reg. Sci. Technol. 16 (3): 309-313. https://0-doi-org.libus.csd.mu.edu/10.1016/0165232X(89)90031-1.

Nixon, W. A., and L. J. Weber. 1991. "Flexural strength of sand-reinforced ice." J. Cold Reg. Eng. 5 (1): 14-27. https://0-doi-org.libus.csd.mu.edu/10.1061/(ASCE)0887-381X(1991)5:1(14).

Nixon, W. A., and L. J. Weber. 1995. "Reinforcement percentage effects on bending strength of soil-ice mixtures." J. Cold Reg. Eng. 9 (3): 152-163. https://0-doiorg.libus.csd.mu.edu/10.1061/(ASCE)0887-381X(1995)9:3(152).

Perutz, M. F. 1948. "A description of the iceberg aircraft carrier and the bearing of the mechanical properties of frozen wood pulp upon some problems of glacier flow." J. Glaciol. 1 (3): 95-104. https://0-doi-org.libus.csd.mu.edu/10.1017/S0022143000007796.

Petrovic, J. J. 2003. "Mechanical properties of ice and snow." J. Mater. Sci. 38 (1): 1-6. https://0-doiorg.libus.csd.mu.edu/10.1023/A:1021134128038.

Pimanmas, A., and S. Saleem. 2019. "Evaluation of existing stress-strain models and modeling of PET FRP-confined concrete." J. Mater. Civ. Eng. 31 (12): 04019303. https://0-doiorg.libus.csd.mu.edu/10.1061/(ASCE)MT.1943-5533.0002941.

Pinto, J. 2016. “'Wow! that's so cool!' The icehotel as organizational trope." Hum. Relat. 69 (4): 891914. https://0-doi-org.libus.csd.mu.edu/10.1177/0018726715618764. 
Pronk, A., M. Mistur, Q. Li, X. Liu, R. Blok, R. Liu, Y. Wu, P. Luo, and Y. Dong. 2019. "The 2017-18 design and construction of ice composite structures in Harbin." Structures 18: 117-127. https://0-doiorg.libus.csd.mu.edu/10.1016/j.istruc.2019.01.020.

Reed, R. P., and M. Golda. 1994. "Cryogenic properties of unidirectional composites." Cryogenics 34 (11): 909-928. https://0-doi-org.libus.csd.mu.edu/10.1016/0011-2275(94)90077-9.

Saleem, S., Q. Hussain, and A. Pimanmas. 2017. "Compressive behavior of PET FRP-confined circular, square, and rectangular concrete columns." J. Compos. Constr. 21 (3): 04016097. https://0-doiorg.libus.csd.mu.edu/10.1061/(ASCE)CC.1943-5614.0000754.

Schulson, E. M. 2001. “Brittle failure of ice.” Eng. Fract. Mech. 68 (17-18): 1839-1887. https://0-doiorg.libus.csd.mu.edu/10.1016/S0013-7944(01)00037-6.

Schulson, E. M., and P. Duval. 2009. Creep and fracture of ice. Cambridge, UK: Cambridge University Press.

Schutz, J. B. 1998. "Properties of composite materials for cryogenic applications." Cryogenics 38 (1): 312. https://0-doi-org.libus.csd.mu.edu/10.1016/S0011-2275(97)00102-1.

Shan, R., Y. Bai, P. Huang, Y. Song, and X. Guo. 2017. "Experimental research on failure criteria of freshwater ice under triaxial compressive stress." [In Chinese.] Chin. J. Theor. Appl. Mech. 49 (2): 467-477.

Shi, J. W., W. H. Cao, L. Chen, and A. L. Li. 2020. "Durability of wet lay-up BFRP single-lap joints subjected to freeze-thaw cycling." Constr. Build. Mater. 238: 117664. https://0-doiorg.libus.csd.mu.edu/10.1016/j.conbuildmat.2019.117664.

Sinha, N. K. 1989. "Elasticity of natural types of polycrystalline ice." Cold Reg. Sci. Technol. 17 (2): 127135. https://0-doi-org.libus.csd.mu.edu/10.1016/S0165-232X(89)80003-5.

Staroszczyk, R. 2019. Ice mechanics for geophysical and civil engineering applications. Basel, Switzerland: Springer.

Teng, J. G., Y. L. Huang, L. Lam, and L. P. Ye. 2007. "Theoretical model for fiber-reinforced polymerconfined concrete." J. Compos. Constr. 11 (2): 201-210. https://0-doiorg.libus.csd.mu.edu/10.1061/(ASCE)1090-0268(2007)11:2(201).

Teng, J. G., T. Jiang, L. Lam, and Y. Z. Luo. 2009. "Refinement of a design-oriented stress-strain model for FRP-confined concrete." J. Compos. Constr. 13 (4): 269-278. https://0-doiorg.libus.csd.mu.edu/10.1061/(ASCE)CC.1943-5614.0000012.

Timco, G. W., and W. F. Weeks. 2010. "A review of the engineering properties of sea ice." Cold Reg. Sci. Technol. 60 (2): 107-129. https://0-doiorg.libus.csd.mu.edu/10.1016/j.coldregions.2009.10.003.

Vasiliev, N. K. 1993. “On development of fibre-ice-composites.” Cold Reg. Sci. Technol. 21 (2): 195-199. https://0-doi-org.libus.csd.mu.edu/10.1016/0165-232X(93)90007-U.

Vasiliev, N. K., A. D. C. Pronk, I. N. Shatalina, F. H. M. E. Janssen, and R. W. G. Houben. 2015. “A review on the development of reinforced ice for use as a building material in cold regions." Cold Reg. Sci. Technol. 115: 56-63. https://0-doiorg.libus.csd.mu.edu/10.1016/j.coldregions.2015.03.006.

Wang, Y., G. Cai, A. S. Larbi, D. Waldmann, K. D. Tsavdaridis, and J. Ran. 2020a. "Monotonic axial compressive behaviour and confinement mechanism of square CFRP-steel tube confined concrete." Eng. Struct. 217: 110802. https://0-doiorg.libus.csd.mu.edu/10.1016/j.engstruct.2020.110802. 
Wang, Y., G. Cai, Y. Li, D. Waldmann, A. S. Larbi, and K. D. Tsavdaridis. 2019. "Behavior of circular fiberreinforced polymer-steel-confined concrete columns subjected to reversed cyclic loads: Experimental studies and finite-element analysis." J. Struct. Eng. 145 (9): 04019085. https://0doi-org.libus.csd.mu.edu/10.1061/(ASCE)ST.1943-541X.0002373.

Wang, Y., G. Chen, B. Wan, G. Cai, and Y. Zhang. 2020b. "Behavior of circular ice-filled self-luminous FRP tubular stub columns under axial compression." Constr. Build. Mater. 232: 117287. https://0-doi-org.libus.csd.mu.edu/10.1016/j.conbuildmat.2019.117287.

Wang, Y., G. Chen, B. Wan, and B. Han. 2020c. "Compressive behavior of circular sawdust-reinforced ice-filled flax FRP tubular short columns." Materials (Basel) 13: 1-21. https://0-doiorg.libus.csd.mu.edu/10.3390/ma13040957.

Wang, Y., G. Chen, B. Wan, and H. Lin. 2018a. "Axial compressive behavior of square ice filled steel tubular stub columns." Constr. Build. Mater. 188: 198-209. https://0-doiorg.libus.csd.mu.edu/10.1016/j.conbuildmat.2018.08.111.

Wang, Y., G. Chen, B. Wan, H. Lin, and J. Zhang. 2018b. "Behavior of innovative circular ice filled steel tubular stub columns under axial compression." Constr. Build. Mater. 171: 680-689. https://0doi-org.libus.csd.mu.edu/10.1016/j.conbuildmat.2018.03.208.

Wang, Y., Y. Wang, B. Wan, B. Han, G. Cai, and R. Chang. 2018c. "Strain and damage self-sensing of basalt fiber reinforced polymer laminates fabricated with carbon nanofibers/epoxy composites under tension." Composites, Part A 113: 40-52. https://0-doiorg.libus.csd.mu.edu/10.1016/j.compositesa.2018.07.017.

Wang, Y., Y. Wang, B. Wan, B. Han, G. Cai, and Z. Li. 2018d. "Properties and mechanisms of self-sensing carbon nanofibers/epoxy composites for structural health monitoring." Compos. Struct. 200: 669-678. https://0-doi-org.libus.csd.mu.edu/10.1016/j.compstruct.2018.05.151.

Wei, Y., Y. Zhang, J. Chai, G. Wu, and Z. Dong. 2020. "Experimental investigation of rectangular concrete-filled fiber reinforced polymer (FRP)-steel composite tube columns for various corner radii." Compos. Struct. 244: 112311. https://0-doiorg.libus.csd.mu.edu/10.1016/j.compstruct.2020.112311.

Wei, Y. Y., and Y. F. Wu. 2012. "Unified stress-strain model of concrete for FRP-confined columns." Constr. Build. Mater. 26 (1): 381-392. https://0-doiorg.libus.csd.mu.edu/10.1016/j.conbuildmat.2011.06.037.

White, G., and A. Mccallum. 2018. "Review of ice and snow runway pavements." Int. J. Pavement Res. Technol. 11 (3): 311-320. https://0-doi-org.libus.csd.mu.edu/10.1016/j.ijprt.2017.11.002.

Wu, Y., X. Lou, X. Liu, and A. Pronk. 2020. "The property of fiber reinforced ice under uniaxial compression." Mater. Struct. 53 (2): 1-15. https://0-doi-org.libus.csd.mu.edu/10.1617/s11527020-01463-2.

Xiao, Y., and H. Wu. 2000. "Compressive behavior of concrete confined by carbon fiber composite jackets." J. Mater. Civ. Eng. 12 (2): 139-146. https://0-doiorg.libus.csd.mu.edu/10.1061/(ASCE)0899-1561(2000)12:2(139).

Xie, P. 2018. "Behavior of large-scale hybrid FRP-concrete-steel double-skin tubular columns subjected to concentric and eccentric compression." Ph.D. thesis, Dept. of Civil and Environmental Engineering, Hong Kong Polytechnic Univ. 
Yu, T., and J. G. Teng. 2011. "Design of concrete-filled FRP tubular columns: Provisions in the Chinese technical code for infrastructure application of FRP composites." J. Compos. Constr. 15 (3): 451-461. https://0-doi-org.libus.csd.mu.edu/10.1061/(ASCE)CC.1943-5614.0000159.

Zeng, J. J., W. Y. Gao, Z. J. Duan, Y. L. Bai, Y. C. Guo, and L. J. Ouyang. 2020a. “Axial compressive behavior of polyethylene terephthalate/carbon FRP-confined seawater sea-sand concrete in circular columns." Constr. Build. Mater. 234: 117383. https://doi.org/10.1016/j.conbuildmat.2019.117383.

Zeng, J. J., Y. Y. Ye, W. Y. Gao, S. T. Smith, and Y. C. Guo. 2020b. "Stress-strain behavior of polyethylene terephthalate fiber-reinforced polymer-confined normal-, high- and ultra high-strength concrete." J. Build. Eng. 30: 101243. https://0-doiorg.libus.csd.mu.edu/10.1016/j.jobe.2020.101243.

Zhang, Y., Y. Wei, J. Bai, G. Wu, and Z. Dong. 2020. "A novel seawater and sea sand concrete filled FRPcarbon steel composite tube column: Concept and behaviour." Compos. Struct. 246: 112421. https://0-doi-org.libus.csd.mu.edu/10.1016/j.compstruct.2020.112421. 